\title{
Clinical and radiological manifestations of 206 patients with pulmonary hydatidosis over a ten-year period
}

\section{Bassam Darwish*}

\author{
Department of Thoracic Surgery, Almouassat University Hospital Medical School, \\ Damascus University, Meze Street 1, Damascus, Syria
}

Received 15 January 2006; accepted 22 May 2006

\section{KEYWORDS}

Clinical manifestation;

Radiological

manifestation;

Hydatid cyst;

Respiratory symptors

\section{Summary}

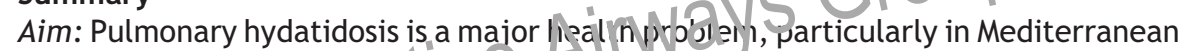
countries, and manifests yith dif erent cinical and radiological forms. The aim of this study was to der tid specific characteriltics o the disease.

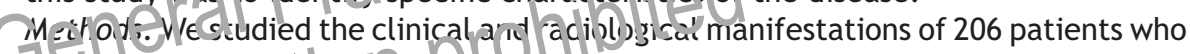

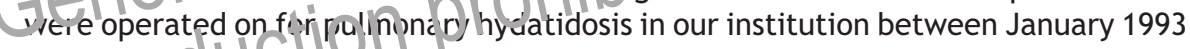
and Decem Del 202.

Pes.1): The clinical presentations were: cough in 112 patients (54\%); chest pain in 75 patients (36\%); dyspnoea in 52 (25\%); haemoptysis in $39(19 \%)$; fever and chills in 21 (10\%); hydatidemesis in 21 (10\%); pleuritis in $11(5 \%)$; and spontaneous pneumothorax in seven patients (3\%). Chest radiograph (CXR) and computerised tomography (CT) established the diagnosis in 184 patients (89\%). Twenty-two patients (11\%) manifested with nonspecific pulmonary shadows.

Conclusion: Hydatid cyst disease has many clinical and radiological forms which should be recognized and included in the differential diagnosis of many pulmonary problems.

(c) 2006 General Practice Airways Group. Published by Elsevier Ltd. All rights reserved.

\section{Introduction}

Hydatidosis is a major health problem in many countries around the world especially in the Mediterranean region [1]. The most frequently

\footnotetext{
* Tel.: +96311 2319718/5252180; fax: +963112121620.

E-mail addresses: dam-uncv@net.sy, bdarwish@scs-net.org.
}

affected site is the liver, followed by the lungs. The disease has different clinical and radiological features.

The aim of this study was to determine the clinical and radiological manifestations of pulmonary hydatidosis in patients treated over a ten-year period in our Thoracic Surgery Department at Almouassat University Hospital in Damascus. 


\section{Methods}

From January 1993 to December 2002, 206 patients with pulmonary hydatidosis (an average of 20 patients per year) underwent surgical intervention. They were studied prospectively for all clinical and radiological presentations on chest radiograph (CXR) and chest computerised tomogram (CT scan). We excluded cases with hydatid cysts located at the dome of the liver although we used the transthoracic approach to remove them. We also excluded all other extrapulmonary hydatidosis cases.

The surgical approach was selected according to the location of the hydatid cysts. Out of the 206 patients, 146 patients $(70.8 \%)$ had isolated unilateral lung cysts, and 60 patients (29.2\%) had coexisting pulmonary and extrapulmonary cysts. 236 operations were performed: all patients with isolated pulmonary hydatid cysts (146 patients) and 33 patients who had multiple pulmonary and extrapulmonary hydatid cysts received a one-stage procedure; a two-stage operative procedure was required for 24 patients (48 operations); and a three-stage procedure for 3 patients ( 9 operations) for multiple cysts.

The pulmonary cysts were usually enucleated intact, the germinal membrane removed, aria the bronchocystic fistulae closed The Oystic cavity was caputonage th t The cavity of any

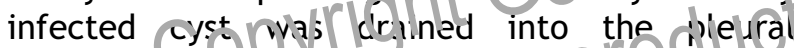
cavity.

The hepatic cysts were injected with hypertonic saline to kill the scolexe, then the fluid sectioned, the germinal membrane removed, and external drainage provided for the rest of the hepatic cavity.

Pharmacological treatment began with albendazole (a dose of $10 \mathrm{mg} / \mathrm{kg}$ weight/day) directly after the hydatid cyst was diagnosed. If the cyst ruptured during the operation we continued with albendazole for up to three months. For ruptured cysts or for co-existing extrapulmonary cysts we continued for six months. For bone, diffuse pleural, or diffuse peritoneal hydatidosis, treatment was given for more than one year.

We stopped the albendazole directly postoperatively if the cysts were enucleated intact. We used praziquentel in a very few cases who had very diffuse hydatidosis.

CXR and CT scan of the chest and abdomen were done in all cases. This helped to exclude all cases of tumours and other benign cysts of the liver. The diagnosis was made mainly radiologically. Serology testing was used to support the diagnosis in equivocal cases. The final diagnosis was based

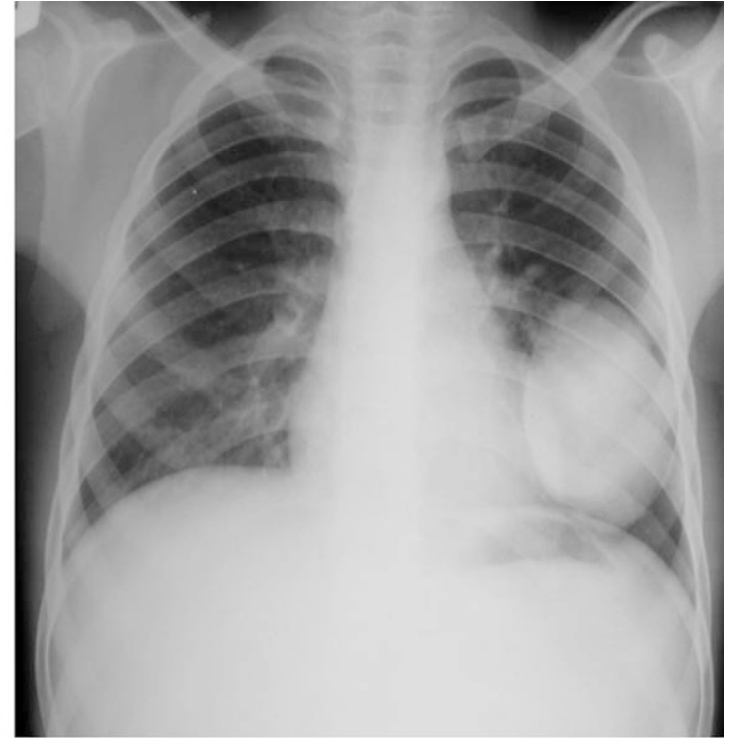

(A)

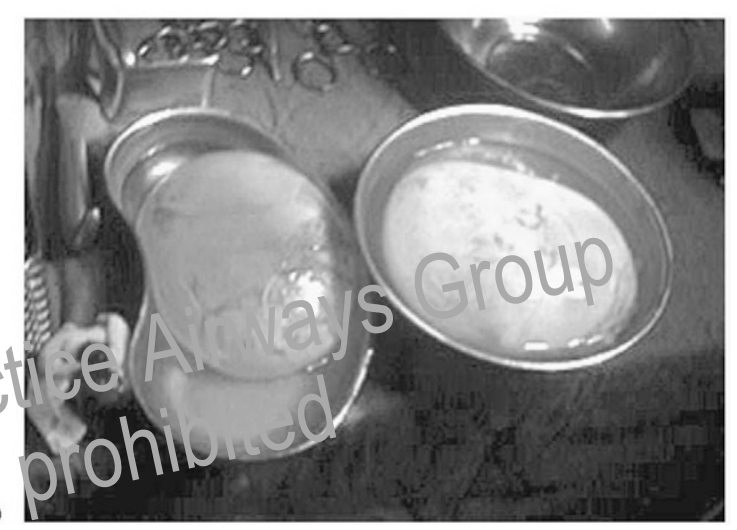

Figure 1 A. Chest X-ray showing an intact pulmonary hydatid cyst (round homogeneous shape and perfectly defined margins in the left lung), enucleated intact through the left thoracotomy in one surgical session. B. Two enucleated cysts from the lung.

on the identification of the germinal membrane grossly or microscopically in surgical or endoscopic specimens (Figures 1-4).

\section{Results}

Of the 206 patients, 83 were male $(40 \%)$ and 123 female $(60 \%)$, and ages ranged from 4 years to 69 years (mean 29.4). One hundred and fifty-six patients $(76 \%)$ had isolated pulmonary cysts only. Of these, 146 (71\%) had unilateral and $10(5 \%)$ had bilateral cysts. The remaining 50 patients (24\%) had, in addition to pulmonary cysts, cysts in the liver (43 patients - 21\%), spleen (12 patients - 6\%), brain (2 patients - 1\%), pericardium (2 patients), myocardium ( 2 patients) and breast (1 patient $0.5 \%)$. 

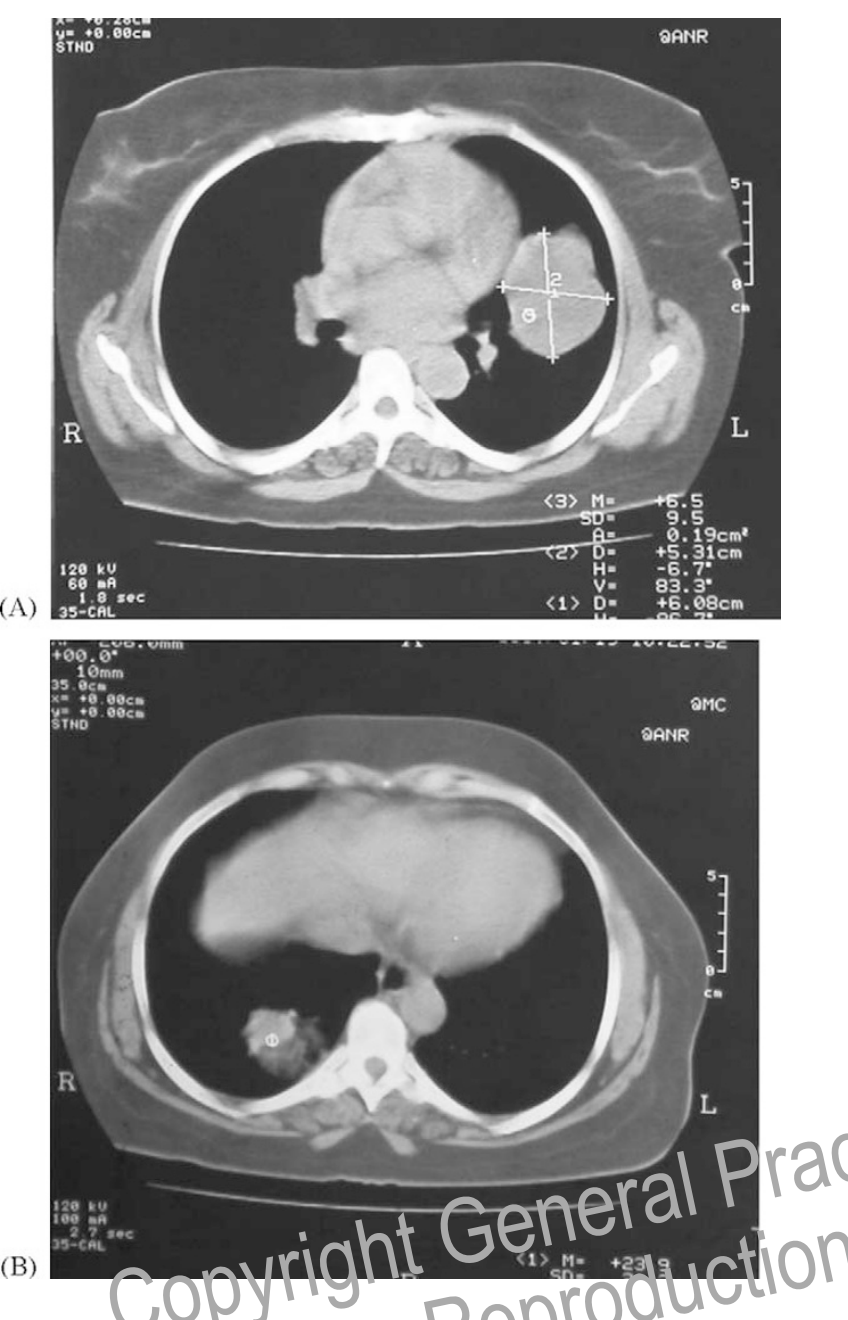

Figure 2 A. Chest CT scan shcwing b !ateral pulmonary cysts. They were removed through median sternotomy in one surgical session. (Homogeneous shape, perfectly defined margins of the intact cyst in the left lung). B. Non-homogeneous shape, undefined margins of the complicated cyst in the right lung.

The length of a typical operation for an isolated pulmonary cyst was around two hours, and for multiple cysts was around three hours. The average hospital stay was 12.6 days. Less time was required for patients who required a one-stage operation, and more time was required for patients who needed multiple operations or who suffered postoperative complications. Neither recurrence nor mortality was recorded.

The diagnosis was made accidentally in 38 patients $(18 \%)$ who were asymptomatic, whilst the remaining 168 patients (82\%) were symptomatic. Presenting symptoms are listed in Table 1 with their corresponding rate of frequency. Cough was mostly dry. Dyspnoea was mild to moderate and rarely severe. Hydatidemesis, which is an important symptom specific to pulmonary hydatidosis, can
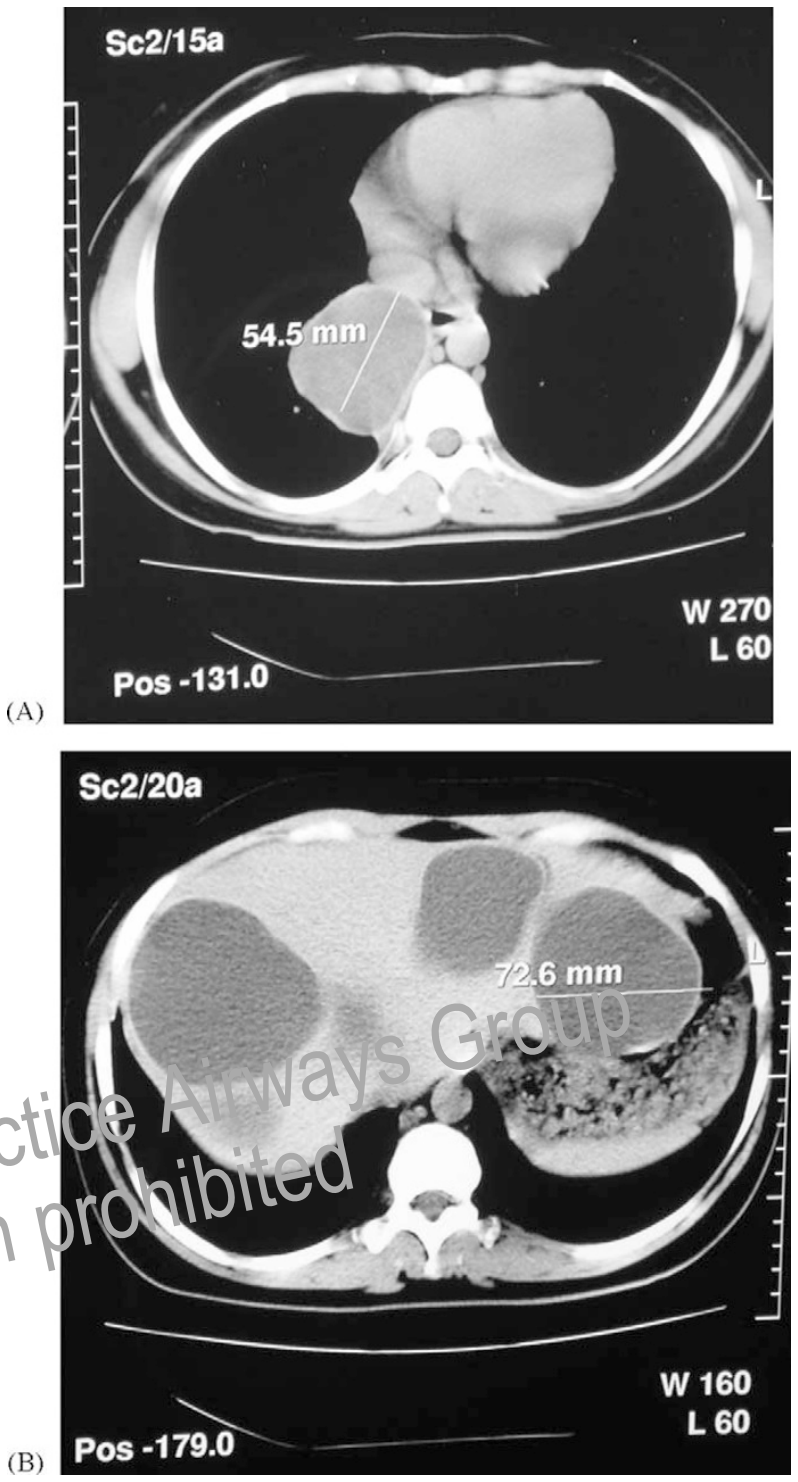

Figure 3 Chest and abdomen CT scans showing pulmonary and hepatic cysts. They were removed through posterolateral thoracotomy and median laparotomy in one surgical session. A. An intact cyst in the right lung near the posterior mediastinum. B. Multiple homogeneous shaped water-dense cysts in the liver, with perfectly defined margins.

Table 1 Clinical presentations in 206 patients with pulmonary hydatidosis

\begin{tabular}{lll}
\hline Symptoms & No. of patients & (\%) \\
\hline Cough & 112 & $(54 \%)$ \\
Chest pain & 75 & $(36 \%)$ \\
Dyspnoea & 52 & $(25 \%)$ \\
Haemoptysis & 39 & $(19 \%)$ \\
Hydatidemesis & 21 & $(10 \%)$ \\
Infectious symptoms & 21 & $(10 \%)$ \\
Pleuritis & 11 & $(5 \%)$ \\
Pneumothorax & 7 & $(3 \%)$ \\
\hline
\end{tabular}




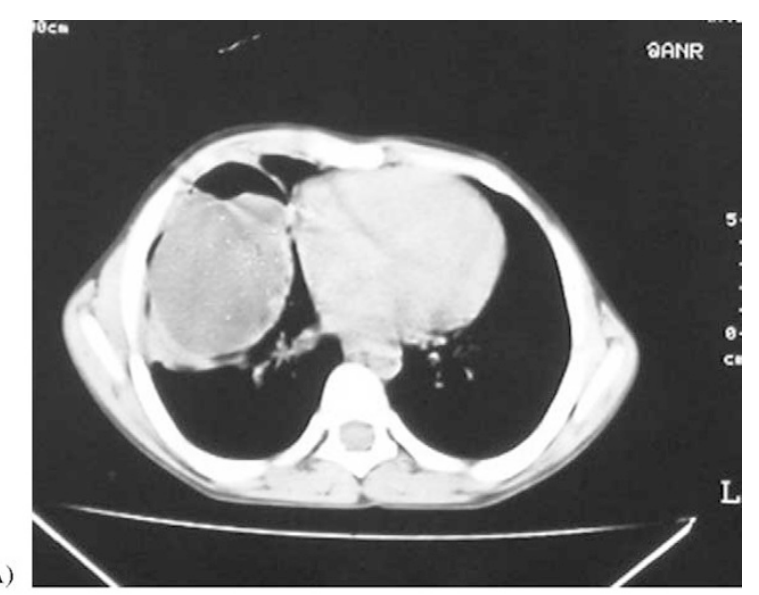

(A)

(B)

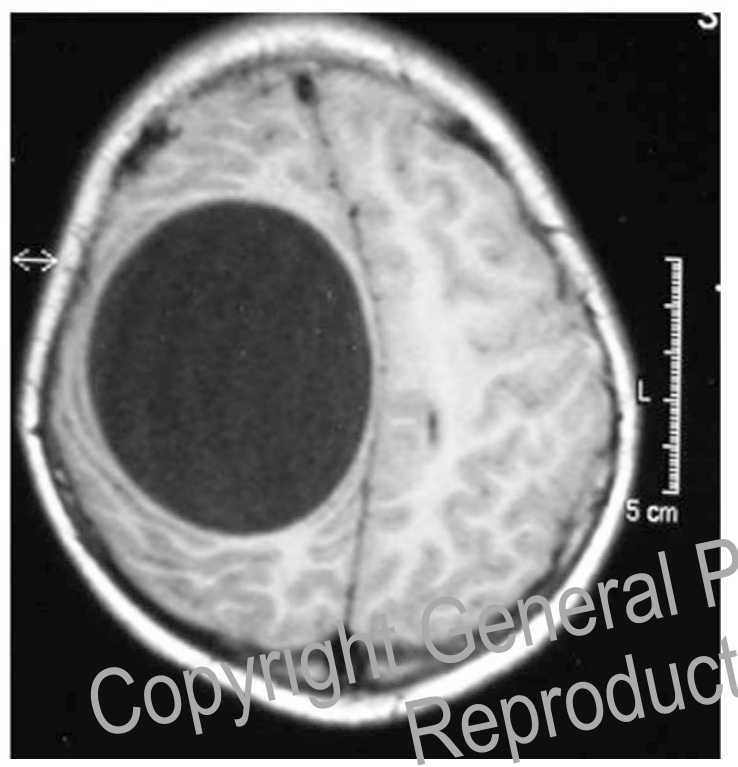

Figure $4 \mathrm{~A}$. Chest CT scan showing complicated pulmonary cyst (an air-fluid level in the cyst in the right lung. B. Brain CT scan showing cerebral cyst (homogeneous shapes, perfectly defined margins with water density in the right brain). They were removed in two surgical sessions: through craniotomy and right thoracotomy after one month. be severe and can cause dyspnoea in very rare cases.

Seven patients presented with pneumothorax resulting from rupture of the hydatid cysts into the pleura ( 2 cases had tension pneumothorax). The pneumothoraces were refractory to chest drainage and needed early thoracotomy to close the bronchopleural fistula.

\section{Discussion}

The most affected organ in hydatidosis is the liver followed by the lungs. Co-existent pulmonary and hepatic hydatidosis varies in the literature between $9 \%$ and $35 \%$ [1-7]. In this study, the rate was $21 \%$.

The third most commonly involved organ in this study was the spleen (6\%), a rate similar to that of Dakak's (5\% [3]), but higher than Safioleas (2\% [6]).

The incidence of asymptomatic pulmonary hydatidosis is reported to be highly variable: $10 \%$ in Tor's study but up to as high as $74 \%$ in Athanassiadi's study [6,9-11]. In our study, the rate was $18 \%$. This variability is not fully expiained b t it it could be partially related to the evele of public medical education, c(El. $)$ J dit diasnosis, and the frequency pOsing screening CXR and abdominal ultrasound, especially in eliceiric areas - see Table 2 .

Tike (nis)t frequently presenting symptom in cur series is cough (54\%). This is similar to most studies reported $[1,10,11]$ - see Table 2 . Other symptoms have lower rates of incidence such as chest pain (36\%), dyspnoea (25\%), haemoptysis (19\%), hydroemesis, infectious symptoms $(10 \%)$, pleuritis (5\%), and pneumothorax (3\%).

Thus, pulmonary hydatidosis can have a wide range of clinical presentations. A chronic cough in endemic areas should prompt a screening CXR and possibly an abdominal ultrasound. Haemoptysis is a

Table 2 Clinical presentations of pulmonary hydatidosis in different studies [13,14]

\begin{tabular}{|c|c|c|c|c|c|c|c|}
\hline Symptoms & Tor Turkey & Solak Turkey & $\begin{array}{l}\text { Safioleas } \\
\text { Turkey }\end{array}$ & $\begin{array}{l}\text { Athorassiadi } \\
\text { Greece }\end{array}$ & $\begin{array}{l}\text { Mikhailova } \\
\text { Sofia }\end{array}$ & $\begin{array}{l}\text { Shalabi } \\
\text { Kuwait }\end{array}$ & $\begin{array}{l}\text { Our study } \\
\text { Syria }\end{array}$ \\
\hline Asymptomatic & $10 \%$ & - & $50 \%$ & $74 \%$ & $38 \%$ & $19 \%$ & $18 \%$ \\
\hline Cough & $54 \%$ & $27 \%$ & - & - & $65 \%$ & $66 \%$ & $54 \%$ \\
\hline Chest pain & $49 \%$ & $14 \%$ & - & - & $33 \%$ & $43 \%$ & $36 \%$ \\
\hline Dyspnoea & $10 \%$ & $14 \%$ & - & - & - & $11 \%$ & $25 \%$ \\
\hline Haemoptysis & $21 \%$ & $33 \%$ & - & - & & $8 \%$ & $19 \%$ \\
\hline Hydroemesis & $5 \%$ & $11 \%$ & $38 \%$ & $6 \%$ & - & $44 \%$ & $10 \%$ \\
\hline Infection & $14 \%$ & $7 \%$ & $2.4 \%$ & $4 \%$ & - & $27 \%$ & $10 \%$ \\
\hline Pleuritis & - & - & - & $9 \%$ & - & - & $5 \%$ \\
\hline Pneumothorax & - & - & $2.4 \%$ & $4 \%$ & - & - & $3 \%$ \\
\hline Total patients & 288 & 110 & 42 & 85 & 196 & 60 & 206 \\
\hline
\end{tabular}


Table 3 Clinical presentations of extrapulmonary hydatid cysts

\begin{tabular}{lll}
\hline Clinical presentations & $\begin{array}{l}\text { No. of } \\
\text { patients }\end{array}$ & $(\%)$ \\
\hline Right upper abdominal pain & 7 & $(3 \%)$ \\
Bilobronchial fistula & 2 & $(1 \%)$ \\
Liver abscess & 1 & $(0.5 \%)$ \\
Right chest pain & 1 & $(0.5 \%)$ \\
Intracranial hypertension & 2 & $(1 \%)$ \\
Breast mass & 1 & $(0.5 \%)$
\end{tabular}

The splenic, cardiac and pericardial hydatid cysts were asymptomatic.

predominant symptom in this study, confirming that one should consider pulmonary hydatidosis in the differential diagnosis of haemoptysis in this setting.

Spontaneous pneumotharax, which may be of the tension-type, was not frequent but was always hard to treat because of the presence of bronchopleural fistulae $[1,6,9-11]$. Future study on the incidence of haemoptysis and pneumothorax resulting from hydatidosis would seem indicated.

We didn't notice any typical anaphylactic symptoms occurring as a result of rupture of cysts into the bronchus or pleura.

Chest radiograph (CXR) and CT scan were used routinely in all patients and were sufficien to establish the diagnosis in $89 \%$ of cases (a: in lact cyst or cyst with an air.fid $\in=v \in(0)[6,0,10]$.

As in our stady, ic (a) and Safioleas repsted th at their main diagnestic metho ds verealso $\mathrm{N} \times \mathrm{R}$ and CT scan $[6,8]$. Mikhailova in his study on 110 children with pulmonary hydatidosis used CXR, CT scan, and ultrasound in $66 \%, 20 \%$, and $12.4 \%$ of patients respectively [10]. It was difficult to diagnose the hydatid cyst in the 22 patients with nonspecific pulmonary shadowing, so that immune testing, bronchoscopy, and identification of the germinal membrane were required to make the diagnosis.

Although the co-existence of pulmonary and hepatic hydatidosis in this series is relatively high, abdominal complaints were relatively uncommon

Table 4 Radiological manifestations of pulmonary hydatidosis in 206 patients

\begin{tabular}{lcc}
\hline Radiological manifestations & $\begin{array}{l}\text { No. of } \\
\text { patients }\end{array}$ & (\%) \\
\hline Intact cyst & 136 & $66 \%$ \\
Air-fluid level & 48 & $23 \%$ \\
Nonspecific shadows & 22 & $11 \%$ \\
Total & 206 & $100 \%$ \\
\hline
\end{tabular}

The radiological examinations established the diagnosis of pulmonary hydatidosis in 184 patients (89\%).
(Table 3). This should alert the treating physician to look for intra-abdominal hydatidosis in all cases of pulmonary hydatidosis regardless of symptoms. This finding has been confirmed in other studies [1-8]. Some hepatic cysts can present with severe symptoms of bilobronchial fistulae. In our study we recognized two such cases. Gerazounis reported 21 cases of bilobronchial fistulae over 20 years [12]. Although this complication is rare, it is very important to recognize it and treat it properly $[2,6,7]$ (Table 4).

\section{Conclusion}

Hydatidosis continues to be a major medical problem in Syria, as in many other Mediterranean countries. Pulmonary hydatidosis can present with various pulmonary symptoms, and should be considered in the differential diagnosis of any patient presenting with these manifestations, especially in endemic areas.

High suspicion should prompt early radiological assessment. Both thoracic and abdominal sites should be evaluated because of the relatively high co-existence of (iisease/cr. both sides of the diaph $c$ m. Haremoptysis, often missed as a Pite:erting symptom of pulmonary hydatidosis, should suggest trifiagnosis especially in the proper se $t i n \&$ fefictory spontaneous pneumothoraces in en iemic areas should lead to a search for a hydatid cyst as a possible underlying cause. Radiological assessment including chest radiograph (CXR) and CT scan identifies most cases.

\section{References}

[1] Aribas OK, Kanat F, Turk E, Kalayci MU. Comparison between pulmonary and hepatopulmonary hydatidosis. Eur J Cardiothorac Surg 2002;21(3):489-96.

[2] Athanassiadi K, Kalavrouziotis G, Loutsidis A, Bellenis I, Exarchos N. Surgical treatment of echinococcosis by a transthoracic approach; a review of 85 cases. Eur $\mathrm{J}$ Cardiothorac Surg 1998;14:134.

[3] Dakak M, Genc O, Gurkok S, Gozubuyuk A, Balkanli K. Surgical treatment for pulmonary hydatidosis (a review of 422 Cases). J R Coll Surg Edinb 2002;47(5):689-92.

[4] Dogan R, Yuksel M, Cetin G, et al. Surgical treatment of hydatid cysts of the lung: Report on 1055 patients. Thorax 1989;44(3):192-9.

[5] Gerazounis M, Athanassiadi K, Metaxas E, Athanassiou M, Kalantzi N. Bronchobiliary fistulae due to echinococcosis. Eur J Cardiothorac Surg 2002;22(2):306-8.

[6] Kabiri EH, El Maslout A, Benosman A. Thoracic rupture of hepatic hydatidosis (123 Cases). Ann Thoracic Surg 2001;72(6):1883-6.

[7] Kilani T, El Hammami S, Horchani $\mathrm{H}$, et al. Hydatid disease of the liver with thoracic involvement. World J Surg 2001;25(1):40-5. 
[8] Mikhailova V, Brankov O, Drebov R, et al. The surgical treatment of pulmonary and associated echinicoccosis in childhood. Khirurgiia (Sofia) 1999;55(2):16.

[9] Novick RJ, Tchervenkov Cl, Wilson JA, Munro DD, Mulder DS. Surgery for thoracic hydatid disease: a North American experience. Ann Thorac Surg 1987;43(6):681-6.

[10] Safioleas M, Misiakos EP, Dosios T, Manti C, Lambrou P, Skalkeas G. Surgical treatment for lung hydatid disease. World J Surg 1999;23(11):1181-5.

[11] Salih OK, Topcuoglu MS, Celik SK, Ulus T, Tokcan A. Surgical treatment of hydatid cysts of the lung: Analysis of 405 patients. Can J Surg 1998;41:131. Can J Surg 1998;41(2):131-5.
[12] Shalabi RI, Ayed AK, Amin M. 15 years surgical management of pulmonary hydatidosis. Ann Thorac Cardiovasc Surg 2002;8(3):131-4.

[13] Solak H, Yeniterzi M, Yuksek T, Anil N, Goktogan T, Ceran S. The hydatid cyst of the lung in children and results of surgical treatment. Thorac Cardiovasc Surg 1990;38(1):45-7.

[14] Tor M, Atasalihi A, Altuntas N, et al. Review of cases with cystic hydatid lung disease in a tertiary referral hospital located in an endemic region: 10 years' experience. Respiration 2000;67(5):539-42.

\section{Available online at http://www.thepcrj.com}

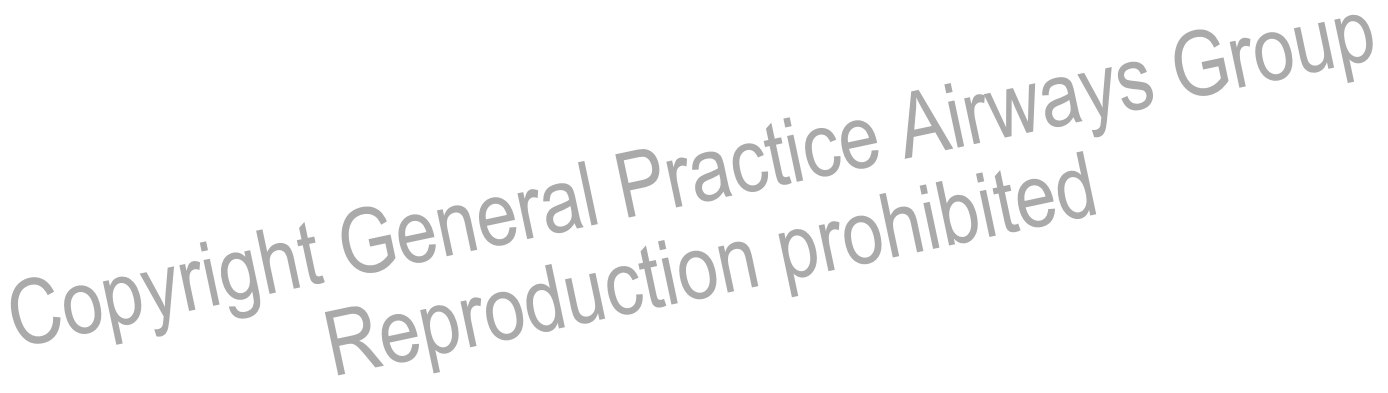

